Send your letters to the Editor,

British Dental Journal,

64 Wimpole Street

London

W1G 8YS

Email bdj@bda.org

Priority will be given to letters less than 500 words long.

Authors must sign the letter, which

may be edited for reasons of space.

\section{NAÏVE ARGUMENT}

Sir, oh dear, where to start? I settled down with interest to read the opinion article People with learning disabilities and specialist services (BDJ 2010; 208: 203-205). Sadly, I was soon disillusioned by what in my opinion is the rather naive argument put forward by the authors. Throughout the paper, definitions (or part of them) and parts of articles are taken out of context and an interpretation is put on them that could not be made were they in the context of the full original text.

The authors seem to have misconstrued the whole ethos of the specialty of special care dentistry (SCD) which is to encourage patient care in primary care services (both by general dental practice teams and dentists with a special interest), and seem to have missed the fact that GDPs may also be specialists. Specialists and consultants in SCD act, as within all other dental specialties, to provide care that the GDP believes is beyond her/his scope; to provide mentoring, training and support to enable members of the dental team to expand their skills set in SCD; and to encourage shared care between the generalist and specialist care providers. Consultants in SCD also take a lead in service development through working with commissioners, providers and users of the service. Above all else, SCD takes a patient-centred approach, putting patient and public engagement (which is a legislative requirement for public bodies anyway) at the heart of service provision and development.

However, rather than go on at length, I will restrict myself to the three points in the 'in brief' box which authors provide as a potted summary of an article's key messages.
Taking them in turn, the first states 'Raises concerns for provision of specialist services for people with a learning disability'. The article puts forward one concern for which it provides no evidence. The next claims that the article 'Discusses the importance of including enhanced payments for GDPs to allow extra time necessary for care'. Not really, it puts it forward as a way of providing more time for non-salaried dentists to be encouraged to provide care for people with a learning disability. Interestingly, incentive payments have been in place in general medical practice in some primary care trusts (PCTs) for the best part of two years now, and they have not worked in the way PCTs had hoped. There has been little increase in provision of an annual health check for people with learning disabilities since the incentive payment introduction. Nor will they work until other barriers, such as practitioner confidence and skills, are addressed. Thirdly, the authors claim the article 'suggests a model of access for primary care organisations when commissioning dental services'. It mentions six dimensions of access. These are well recognised and were distilled from the seminal works of Penchansky, Thomas and Maxwell in the early 1980s. However, the article goes no further in its explanation of how these domains are configured into the model'. Indeed, the reader is referred to a yet unpublished paper for further details. The usual practice of using published evidence to support the argument allows the reader to refer to it for further information. I look forward to gaining a better understanding of the proposed model for improving access by reading the article Access to dental services for people with learning disabilities: quality care? in its entirety, although I may have to wait a while as I note that it was only submitted for consideration for publication in November 2009.

J. Fiske MBE, by email DOI: 10.1038/sj.bdj.2010.505

\section{INSUFFICIENT INSIGHT}

Sir, the opinion piece People with learning disabilities... by Owens, Dyer and Mistry (BDJ 2010; 208: 203-205) reminds us of the inequalities in access to dental care faced by people with learning disabilities (PwaLD). However, its assertion that the speciality of special care dentistry (SCD) will adversely affect access to dental care is misguided and it shows insufficient insight into the reasons why people with a learning disability do not access dental care.

Its fundamental mistake is to treat access to dental care in isolation and not to acknowledge the lack of access to a full range of health services and the unsatisfactory care often experienced. ${ }^{1}$ The previous work on access to dental services for people with learning disabilities, carried out by the salaried dental services and learning disability services in Sheffield $^{2}$ involved extensive collaborative effort between dental services and community learning disability teams. Other studies have shown that the issues are more complex than simply making dental services more accessible. ${ }^{3}$ Well resourced Community Learning Disability Nursing Teams are essential in facilitating access to health services and this of course would include dental services. Community based consultants and specialists in SCD not only have a role in treating the most complex PwaLD but have an important leadership role. They should be involved in developing pathways of 
care and influencing commissioners in improving access to care for special care groups and in facilitating collaborative working between a wide variety of agencies in contact with special care groups. Consultants, specialists and special care SDOs in salaried services have a public health role. They will know or assess the needs of their target groups and attempt to work with commissioners to ensure special care groups can access care in the most appropriate setting. The British Society for Disability and Oral Health (BSDH) has guidelines on both pathways of care for PwaLD and Commissioning SCD services, ${ }^{4,5}$ which are used by specialists to develop local services. Specialists or consultants can develop referral criteria for access to specialist services, so the authors need not worry that PwaLD who could be treated in general practice, would be automatically referred for expensive specialist care.

Simply incentivising GDPs, presumably with enhanced UDA values, will not significantly improve access and is too simplistic a view. I agree that GDPs can have an important role in improving the access to dental care for PwaLD but cash can only be a small part of encouraging them to accept PwaLD as patients in their practice.

Improved knowledge and confidence, in the form of good undergraduate training in SCD, would be the foundation of improving access to special care groups and BSDH actively supports undergraduate training in SCD. However, not all dental schools participate in BSDH's SCD teaching support activities and it is clear that some could improve their undergraduate curricula. When PwaLD are asked their views on what they consider good dental care they talk about the personal qualities and communication skills of their ideal dentist. Advanced clinical skills are not required; PwaLD want what much of the population do - a nice dentist who can communicate effectively with them, treat their wishes with respect and guide them through worrying procedures with sensitivity and care. $^{6}$ I would argue this is within the skills of the vast majority of GDPs and that many already treat PwaLD within their practices. Whilst many may not be confident about treating PwaLD, they may be more inclined to do so if they felt they had access to local support. A specialist or consultant could provide this support for all kind of special care groups, not only those with learning disabilities. The trick is in collaborating widely to ensure PwaLD can access care in the most appropriate setting.

The authors mention the Steele Report ${ }^{7}$ but this was disappointing in that it had little to say about how it proposed to improve access to care for disabled groups. It does not identify disabled access to dental practices in its performance indicators. It has not considered the BDA's Case Mix model as a useful tool to measure and monitor case complexity.

Unfortunately, I could not see the proposed model of access in the authors' piece. Hopefully, this will become clear on publication of their paper. Their opinions would be more usefully expressed within the discussion and conclusions of the study they cite, rather than beforehand. Then we may be able to assess if their assertions are supported by the evidence they present. I would suggest they include support for highly stretched Community Learning Disability Nurses, who are worth their weight in gold, in my experience.

\section{S. Tiller, BSDH}

1. MENCAP. Death by indifference. March 2007 http://www. mencap.org.uk/document.asp?id =284

2. Tiller S, Wilson K I, Gallagher J E. Oral health status and dental service use of adults with learning disabilities living in residential institutions and in the community. Community Dent Health 2001; 18: 167-171.

3. Pratelli P, Gelbier S. Dental services for adults with a learning disability: care managers' experiences and opinions. Community Dent Health 1998: 15: 281-285

4. British Society of Disability and Oral Health/Faculty of Dental Surgery, RCS. Clinical guidelines \& integrated care pathways for the oral health care of people with learning disabilities 2001. http:// www.bsdh.org.uk/guidelines/Dianatru.pdf

5. British Society of Disability and Oral Health. Commissioning Tool for Special Care Dentistry, 2006. http://www.bsdh.org.uk/misc/Commissioning_Tool_for_Special_Care_Dentistry_FINAL_ MARCH_2007.pdf

6. Cumella S, Ransford N, Lyons J, Burnham H. Needs for oral care among people with intellectual disability not in contact with Community Dental Services. J Intellect Disabil Res 2000; 44: 45-52.

7. Department of Health. NHS Dental Services in England: an independent review led by Professor Jimmy Steele. London, 2009.

J. Owens, T. Dyer and K. Mistry respond to the above two letters: We would like to thank J. Fiske and S. Tiller for their comments. Although different in tone, the letters raise similar issues and so we respond in one letter. We concur that inequalities are at the heart of the matter and welcome the discourse that our opinion piece has started. We support the establishment of the specialty of special care dentistry which we state is timely and much needed', and do not dispute the need for specialist services. Our concern centres on the service user and what can be done to enable them and to improve their inclusion in and access to quality services. Moreover, we are fully aware that the reasons why people with learning difficulties do not access dental care are complex and multifactorial, and whilst dental care should not be seen in isolation from a whole person approach, it is an unfortunate reality that this often occurs.

There is a large amount of anecdotal and observational evidence that specialist services stimulate referrals. Our concern is that anyone with a disabled 'label' may be referred thereby restricting choice and inclusion. Key principles in any referral process include that the skills and judgement of the dentist are considered (in order to maintain clinical autonomy and decision-making) and that it is tailored to patients' individual needs. People with learning difficulties' views are often overshadowed by issues of competence, risk and their ability/ inability to manage their own health. We acknowledge, and our data confirm, that GDPs can routinely care for people with learning difficulties and provide high quality care. However, even when specialists are involved in developing services and guidelines have been agreed, patient preferences can still be marginalised..$^{1-5}$ Planning is obviously an important start, but there also needs to be commitment to resource support services that people with learning difficulties need to ensure we do not restrict choice and further disable the people we seek to enable.

As J. Fiske describes, we discuss the definitions of disability, particularly learning disability, and their tendency to follow a medical model by focusing on deficit and treating everyone with the label as the same. The JASCD's definition: 'Individuals and groups in society who have a physical, sensory, intellectual, mental, medical, emotional or social impairment or disability or more often a combination of a number of these factors', unintentionally implies that 
people with disabilities are a homogenous group. Whilst it is important to consider groups who have common concerns, we also need to acknowledge that they are unique individuals with differing needs who face barriers to inclusion. ${ }^{2}$

Putting the person at the centre of decision-making processes is a key principle of Valuing people, ${ }^{6}$ and when applied to healthcare this should result in the optimum delivery of patient-centred care. ${ }^{7,8}$ However, such an approach often assumes service users are articulate individuals who can describe, understand, and account for their symptoms of illness. Many people with profound cognitive impairments may be unable to comprehend or articulate changes to their own health. Furthermore, many with learning disabilities are reliant on a third party to explain their healthcare difficulties. ${ }^{9}$ Enabling general practitioners to take the time to get to know the person as an individual by enhanced payments is simplistic but there has to be an element of recompense for the extra time required. For example, employing communication aids, getting to know how that person communicates the best, or even taking consent may be a lengthy process with someone with impaired communication. A whole community approach needs to be employed in order for specialist services not to become overloaded, whilst simultaneously valuing GDPs and enabling people with learning disabilities by offering choice and inclusion in mainstream services wherever possible. For all kinds of reasons, we would like to see a contract that better reflects the principles of the NHS, but realistically there is not going to be significant change in the short to medium term. If we are committed to improving access and healthcare for people with learning disabilities then giving GDPs and primary care commissioning organisations room for manoeuvre by incentivising within the existing contract is essential. A complementary approach might be a performance indicator in a quality framework to monitor the number of patients with learning difficulties cared for. Obviously, this brings back the problem of definition, but it is another possible measure.

The seminal works of Penchansky, Thomas $^{10}$ and Maxwell ${ }^{11}$ may be familiar to some, but that does not mean that the principles on which they are based do not have relevance today. Our qualitative data suggest that there was good practice under all six dimensions of 'access'. However, there was also evidence of barriers to access and a failure to acknowledge the needs and preferences of those with learning disabilities by both general dental and salaried dental services. It would appear that while policy and guidance are available, ${ }^{6,12-14}$ there is still a long way to go before we can say that oral healthcare for those with learning difficulties is high quality.

As we write this letter we await the reviews of our research article which was submitted in November 2009. Unfortunately some journals have a quicker turnaround for reviewing and publication than others which resulted in the early publication of our opinion piece. We look forward to being able to share our research findings once accepted for publication.

1. LDRI: Grant G, Ramcharan P.Valuing people and research: the Learning Disability Research Initiative - overview report. London: Department of Health, 2007.

2. Marks B Oakes B Commentary on healthcare for all: the independent inquiry into access to healthcare for people with learning disabilities. Tizard Learning Disability Review 2008;13: 35-37.

3. Grant $G$, Ramcharan P. Valuing people and research: outcomes of the Learning Disability Research Initiative. Tizard Learning Disability Review 2009: 14: 25-34.

4. Dawkins B. Valuing Tom: will valuing people now change the lives of people with profound and multiple disabilities?Tizard Learning Disability Review 2009; 14: 3-12.

5. Owens J, Mistry K, Dyer T. Access to dental services for people with learning disabilities: quality care? J Disabil Oral Health; submitted November 2009.

6. Department of Health. Valuing people. A new strategy for learning disability for the 21st century. A White Paper. Cm 5086. The Stationery Office, 2001.

7. Stewart M, Brown J B, Weston W W, McWhinney IR et al. Patient-centered medicine. Transforming the clinical method. Radcliffe Medical Press, 2003.

8. Winefield HR, Murrell T, Clifford J, Farmer E. The search for reliable and valid measures of patientcentredness. Psychol Health 1996; 11: 811-824.

9. Keywood K, Fovargue S, Flynn M. Best practice? Health care decision-making by, with and for adults with learning disabilities. Manchester: National Development Team, 1999.

10. Penchansky R, Thomas JW. The concept of access: definition and relationships to consumer satisfaction. Med Care 1981; 19: 127-140.

11. Maxwell R J. Quality assessment in health. Br Med J 1984:288: 1470-1472.

12. British Society of Disability and Oral Health/Faculty of Dental Surgery, RCS. Clinical guidelines \& integrated care pathways for the oral health care of people with learning disabilities 2001. http:// www.bsdh.org.uk/guidelines/Dianatru.pdf

13. British Society of Disability and Oral Health. Commissioning Tool for Special Care Dentistry, 2006. http:// www.bsdh.org.uk/misc/Commissioning_Tool_for_ Special_Care_Dentistry_FINAL_MARCH_2007.pdf

14. Department of Health. Valuing people's oral health. Gateway ref: 8660. London: Her Majesty's Stationery Office, 2007

DOI: 10.1038/sj.bdj.2010.506 